\title{
Анжсега Хохлова
}

\section{КОНЦЕПТОСФЕРА МУЗЫКАЛЬНОГО ИСКУССТВА}

Когнитивное исследование сушностных характеристик пространства музыкального искусства, в котором физическая и психическая реальности объединяются в акте переживания, увлекательный проџесс. Он предполагает распутывание коллизий его бытия в культуре, анализ константных (музыка как текст культуры) и релятивных (смыслообразование в контексте музыкального бытия) единств, обнаружение пропозиџиональных структур (ментальных единиј, характеризующих взаимоотношения субъекта познания с окружаюшим миром).

В постижении смысла музыкального текста важно выявить базовые культурные конџепты и фундаментальные стереотипы сознания как неотъемлемые составляющие музыкальной конџептосферы. В широком плане они выходят за пределы собственно музыки и охватывают закономерности, свойственные другим явлениям действительности.

Конџептосфера музыкального искусства как своеобразное семантическое поле культуры содержит в «свернутом», закодированном виде особенности культурных эпох и стилей, их мировоззренческое и духовное содержание, откристаллизовавшиеся типические элементы музыкального языка и речи, формируюшие представления об особенностях музыкального мышления и мировосприятия.
Адекватное прочтение произведения музыкального искусства в настояшее время может базироваться на современных научных данных в области междисџиплинарного знания, уверенно подтверждаюшего реальность существования конџептосферы и составляющих ее конџептов - неких абстрактных сущностей в сознании человека, обобщающих разнообразные признаки мира действительности.

Сам конџепт является достаточно изученної когнитивной единиџеї, функџионирующей в мыслительном процессе. В разных философских и лингвистических учениях на сегодняшний день существует множество определений понятия кониепт.

Одна из дефиниџий восходит к П. Абеляру, яркому представителю духовной жизни Средневековья, который рассматривал конџепт как форму «схватывания» смысла, как «связывание высказываний в одну точку зрения на тот или иной предмет при определяющей роли ума, преобразуюшего высказывания в льнушую к Богу мысль». Конџепт, по мысли Абеляра, формируется речью, освященной Святым Духом, и потому осушествляется «По ту сторону» грамматики или языка в пространстве души с ее ритмами, энергией, интонаџией [15, с. 141].

В 30-х годах прошлого столетия С. Аскольдов справедливо подчеркивал, 
что вопрос о природе конџептов (общих понятий) или, по средневековой терминологии, - универсалиі, уже в то время был не новым. Известный представитель субъективного идеализма понимал конџепт как мысленное образование, замещающее в проџессе мышления неопределенное множество предметов одного и того же рода [2, с. 267].

Российский ученый, филолог, семиотик Ю. Степанов считал, что конџепт - это основная ячейка культуры в метальном мире человека, «пучок представлениї», знаниї, ассоџиаџй, переживаниі, сопровождающй его наименование [19, с. 40]. В таком понимании роль языка представлялась второстепенной. Язык рассматривался как вспомогательное средство, форма «оязыковления» сгустка культуры, конџепта.

В последнее десятилетие XX века понятие кониепт вновь актуализируется и переосмысливается, что знаменует новый этап в изучении способов и закономерностей взаимодействия языка, сознания и культуры, следовательно - акџентуаџию новых аспектов взаимосвязи лингвистики, когнитологии, культурологии, а также психологии, философии и других наук.

Представители «антропологической лингвистики» Н. Арутюнова, Т. Булыгина, А. Шмелев и Н. Алефиренко постулируют семантический подход к конџепту, трактуя его как единицу когнитивной семантики. Языковые данные в проџессе теоретических исследований постоянно соотносятся с опытными сенсомоторными показателями и рас- сматриваются на широком фоне культурологического, соџиологического, биологического и психологического порядка.

Согласно Е. Кубрякової, конџепт является результатом столкновения значения слова с личным опытом человека. Известный лингвист-когнитолог считает, что конџепт - оперативная содержательная единиџа памяти ментального лексикона, конџептуальной системы мозга (lingva mentalis), всей картины мира, отраженной в человеческой психике [5]. Это определение корреспондирует с определением В. Телия. С точки зрения ведущего спеџиалиста по проблемам номинаџии, семантики и прагматики языковых единиџ, конуепт - продукт человеческой мысли и явление идеальное, присущее человеческому сознанию вообще, а не только языковому. Это конструкт, который не воссоздается, а реконструируется через свое языковое выражение и внеязыковое знание [20].

Отсутствие единого определения можно объяснить тем, что конџепт характеризуется достаточно сложной структурой. Она содержит, наряду с понятийной основой, важные соџиальные, психические и культурные составляющие, которые мыслятся и переживаются носителем языка, включает эмоџии, ассоџиаџии, оџенки, образы и коннотаџии, присущие той или иной культуре. Исходя из проанализированных дефиниџий, следует, что конџепт - это понятие, погруженное в культуру, обладающее эмотивностью, аксиологичностью и имеющее имя в языке.

А. Амрахова, автор первого в отечественної музыкальной науке фунда- 
ментального труда, посвяшенного когнитивным аспектам интерпретаџии современной музыки, әффективно используеттерминкониеептприменительно к музыкальному искусству. Обращаясь к «минимальному смыслообразуюшему “кирпичику” новой научной парадигмы», исследователь отмечает, что «конџепт - это не слово, он гораздо шире по своему смысловому объему», «концепт тяготеет к вероятностным образам и направлен на них, так как постоянно видоизменяется в своей извечной готовности вступать в новые ассоџиативные связи. В художественном конџепте “родовое" может быть не всегда выражено, чаше - это пересечение ассоџиативно заряженных образов» [1, с. 43].

Как утверждает Амрахова, «сегодня мало у кого вызывает сомнение тот факт, что конџепт - это “душа” смыслонесущего ментального акта» [1, c. 42]. В своем исследовании музыковед опирается на прототипическую семантику как на «одну из тех немногочисленных методологий, способных не только описывать особенности конџептуализации человеком действительности, но и моделировать наиболее вероятные способы функџионирования интерпретирующего сознания [1, с. 25].

По мысли современного филолога В. Масловой, «конџепты как интерпретаторы смыслов» всегда «поддаются дальнейшему уточнению и модификаџиям», «они представляют собой реализируемые сущности только в начале своего появления, но затем, оказываясь частью системы, попадают под влияние других конџептов и сами видоизменяются» [8, с. 39].
В качестве примера Маслова приводит такой конџептуальный признак, как краснызи. С одной стороны, он интерпретируется как признак понятия ивет (выработанного зрением человека в проџессе распознавания различных предметов внешнего мира), с другой обогащается новыми характеристиками путем уточнения интенсивности своего цветового тона (пурпурный, алый, багряный и т.д.).

Применительно к музыке, обратимся к такому конџептуальному признаку, как тембральныци. Он истолковывается как признак понятия окрас, в данном случае выработанного слухом человека и характеризующего звук музыкального инструмента или голоса («хрустальный», «мягкий», «нежный» в отношении звучания флейты, «яркий», «резкий» — трубы, «матовый», «глухой» - гобоя, «хриплый», «глу бокий», «бархатный» - фагота и т.д.). Этот признак обретает бо́льшую определенность, обогащаясь новыми характеристиками в связи с конкретным инструментом, совокупностью признаков различных звуков, извлекаемых на нем, включая приемы исполнения (к примеру, на фаготе - двойное и тройное стаккато, четвертитоновая интонаџия и др., востребованные в сочинениях композиторов-авангардистов).

Расширяя представление о конџепте, можно утверждать, что концепт многомерное образование, включающее не только понятийно-дефиниџионные, эмотивные и аксиологические характеристики, но и коннотативные (от лат. connotatio - добавочное значение, 
в смысле сопутствуюшего значения языковой единиџы), образные, ассоџиативные референџии.

Как верно указал Р. Павиленис, «усвоить некоторый смысл (конџепт) значит, построить некоторую структуру», иными словами, «конџептуальную систему», «состоящую из имеющихся конџептов в качестве интерпретаторов, или анализаторов, рассматриваемого конџепта, вводимого - с “внешней” точки зрения», то есть с позиџий «некоего наблюдателя, находящегося вне системы» [16, с. 101-102]. Используя понятие кониелтуальная система, ученый фактически ведет речь о кониеептосфере как о подвижной системе мнений и знаний человека о мире, отражающих его познавательный опыт на доязыковом и языковом уровнях.

Если конџепты - это «ячейки культуры», «сгустки» культурных смыслов (С тепанов), то очевидно, что их изучение способствует выявлению особенностей мировосприятия человека и формированию его представлений о конџептуальной картине мироздания.

Важным фрагментом конџептуальной картины мира, как известно, является стереотип (зафиксированная мыслительная конструкџия, автоматическая умственная реакџия на что-либо), существующй в сознании индивида в виде «условной <..> идеи, которая содержит необходимый <..> объем знаний об объектах соответствующего ему класса» [Џит. по: 22, с. 146]. Стереотип как когнитивноязыковой феномен можно рассматривать в двух аспектах: как относитель- но устойчивый принятый в исторической общности образеџ интерпретаџии информаџии, основанный на предшествуюшем соџиальном опыте, или как культурно-детерминированное представление, существующее в виде вербальной оболочки и в виде ментального образа.

Апелляџия к реалиям человеческого сознания в проџессе интерпретаџии музыкального текста необходима для подбора направляющих ассоџиативное мышление с џелью дополнения когнитивной сети смысловых разверток. Если исходить из идеи о том, что стереотипы сознания - это часть мировоззрения, которая может рассматриваться как носитель коллективных представлений или как проявление имплиџитных знаний о мироустройстве, то окажется, что за любой единиџей языка стоит некий стереотип, а вся ассоџиативно-вербальная сеть представляет собой «стереотипное поле», представляющее конџептосферу того или иного наџиональнолингво-культурного сообшества.

Известно, что понятие кониеептосфера было введено в отечественную науку академиком Д. Лихачевым. По определению ученого, конџептосфера - это «совокупность конџептов нации, образованная возможными потенџиями конџептов носителей языка. Чем богаче культура наџии, ее исторический опыт, фольклор, изобразительное искусство, литература, наука, религия, тем богаче конџептосфера народа» [6, с. 5].

В понимании Масловой конџептосфера предстает как «совокупность 
конџептов, из которых, как из мозаичного полотна, складывается миропонимание носителя языка» [8, с. 69]. В интерпретаџии 3. Поповой и И. С тернина, изучающих различные направления когнитивной лингвистики, кониеептосфера предстает как ментальное поле, которое состоит из конџептов - неких когнитивных структур, сушествуюших в виде мыслительных картинок в сознании человека.

Сегодня понятие кониеептосфера допускает множественное толкование, которое сводится к следуюшему: конџептосфера - это сфера мыслительных образов (схем, сџенариев, фреймов), единиџ универсального предметного кода, которые представляют собой структурированное знание индивида, его информаџионный базис. Приходит понимание того факта, что конџептосфера может быть репрезентирована не только системой языковых знаков, но и иными знаковыми системами культуры (жесты и мимика, музыка и живопись, скульптура и танец и др.).

При рассмотрении музыкальної знаковой системы необходимо учитывать, что каждое музыкальное послание, зафиксированное в виде нотного текста или разворачиваемое в акустической форме, являет собой спеџифический художественный код. Посредством его интерпретаџии в условиях определенной культурной эпохи выявляются смыслообразуюшие основы музыкального текста, соответствуюшие композиторскому замыслу и одновременно выходящие за его рамки.

Расширение граниџ познания музыкального произведения предопреде- ляется его преобразованием во времени, связанным со своеобразным движением художественных кодов в культуре. То есть музыкальное искусство меняется вместе с культурой, а с ними - концептосфера музыкальных творений, их контекстные смысловые поля и собственно познающий субъект, его мышление и мировосприятие.

Особенности музыковедческого понимания конџептосферы определяются его погружением в сферу музыки. В данном контексте кониегтосфера музыкального искусства - это система культурных смыслов (конйептов), которые, являясь структурньми единицами художественного мира, отражают специифику создания, бытования, слушательской рецепиии, воплощления и воспроизведения музыкального текста в культуре.

К определению смысловых граниџ понятия конџептосфера музыкального искусства можно подойти и с позиџий когнитивного толка. В таком ракурсе кониептосфера музыкального искусства предстает как информационная база музыкального мышления, органи зуюшиая многообразные смыслы мироустройства и музыковедческие смысльи в этом мироустройстве.

Когнитивный подход к изучению этих смыслов способствует формированию спеџиального знания в широком цивилизаџионном контексте, позволяет вскрыть причины и механизмы динамических проџессов в сфере музыкального мышления и восприятия с учетом меняюшейся исторической потребности 
человека в общественно-музыкальной коммуникаџии.

Специфическое знание с необходимостью включает в себя все виды музыкального творчества в связи с совокупностью их музыкально-выразительных средств (музыкальный язык, принципы формообразования, композиџионные приемы), способом и условиями исполнения, особенностями восприятия, генезисом и эволюџией.

Базовыми конџептами в музыке выступают такие музыковедческие категории, как стиль, жанр, форма, композиция и др. Они устанавливают внутренние взаимосвязи конџептосферы музыкального искусства, раскрывающие особенности культуры эпохи. Эти конџепты - понимаемые понятия (А. 人осев), имплиџитно формирующи еся у индивида в проџессе соџиализаџии и служашие мыслительным инструментарием для человека каждой конкретной эпохи. Они задают систему координат, исходя из которой, человек воспринимает явления действительности и сводит их в своем сознании воедино.

Содержание современной музыкальной науки свидетельствует о необходимости пересмотра сложившихся в вопросе изучения музыкальных универсалий, установок и требует всестороннего изучения данных феноменов. Наиболее эффективным инструментом для музыкознания в изучении категорий стиля, жанра, формы и композийии является конџепт. Ж. Делез писал, что конуепт - это «некое чистое Событие», он «абсолютен как целостность, но относителен в своей фрагмен- тарности, он самоподобен аналогично структурам фрактальной геометрии и содержит составляющие, которые также могут быть взяты в качестве конџептов, поэтому он бесконечно вариативен» [Џит по: 3, с. 33-34]. Особенно важным представляется, что конџепт (в отличие от понятия) связывает смысловое многообразие изучаемых явлений в некое объективное единство.

Если классическое толкование подразумевает стиль как единство объективно-всеобщего с субъективноличностным, как структуру, придающую культуре определенность, то когнитивная система представлений приводит к осознанию того, что суть постижения стиля должна выражаться постижением его конџептуальной основы, не поиском закономерностей, а пониманием, направленным на выявление смыслов объективної данности.

По справедливому утверждению Амраховой, «поиск когнитивных истоков стилеобразования может стать важнейшим принџипом культурноисторической рефлексии, позволяя с достаточной степенью точности эксплицировать то, что может быть сказано в данной культурно-исторической среде, данной поэтикой» [1, с. 186].

При обращении к камерно-инструментальной музыке - одной из основных составляющих мировой музыкальной культуры - становится очевидным, что она имеет свою соџиально-историческую и семантико-эстетическую спеџифику. Семантика жанрової сферы камерной музыки связана с условиями ее бытования (увеселение узкого круга 
слушателей небольшим составом исполнителей в домашней обстановке), носит следы обшности занимаюшихся музыкальной деятельностью людей, локализуемой в исторических, культурных и соџиальных координатах. Ее микрокосм направлен на интеграџию - исполнителей и слушателей, голосов партитуры, музыкальных тем и мотивов.

В категориальной организајии ее восприятия наиболее важным представляется вопрос о стилевых и жанровых инвариантах, которые существуют в исторической памяти музыкальной культуры и в художественном сознании как некие самостоятельные данности. Довольно широкий диапазон их интерпретаџии обусловливает многоаспектность проблем стиля и жанра в ансамблевой музыке.

Во всех смысловых разновидностях конџепта стиль (исполнительский стиль, стиль эпохи, авторский стиль и т.п.) непременно предполагает ся единый генезис. Совокупность музыкальных явлений (ансамблевых произведений) необходимым образом соотносится с породнившими эти явления источниками: сферой распространения, определенной эпохой, жанровым локусом, творчеством конкретного композитора и т.д.

Исполнительский стиль в коллективном музиџировании оказывается изначально обобшенным, но каждый из играющих, подчиняясь общему замыслу, одновременно интонирует и утверждает себя как индивидуальность. Стиль эпохи всегда дается в вертикальных координатах исторического пространства- времени как индикатор сменяюших друг друга локусов культуры. Авторский стиль горизонтален. В его собственном континууме перекликаются и сталкиваются культурные парадигмы, обретая узнаваемость и персонифицированное значение.

Для обнаружения общепринятого или индивидуального стилевого инварианта структурной организаџии музыкального целого важно собственно понимание конџепта стиль как формы выражения историко-культурных знаний в широчайшем комплексе знаний о мироустройстве. В этом контексте содержание, сущность и функџии стиля переосмысливаются.

В ракурсе современной познавательной парадигмы стиль предстает как инстоумент интерпретации, способствующиий устроению смыслового пространства культуры в ходе рефлексии субъекта, который обду мывает бытие как личную субъективную действительность, реальность духовного мира, образованную взаимоотношениями между множественными индивидуальными и коллективньми мирами.

Когнитивные основания, приведшие к новой интерпретаџии понятия стиль, закладывались мыслителями на протяжении столетий. В настоящее время становится очевидным, что некоторые исторические трактовки стиля можно связать с попытками постижения эволюџии џелостной системы человек культура - образ мира.

К примеру, франџузский ученый Ж. $ᄉ$. Бюффон считал, что стиль яв- 
ляется не просто отражением, но и моделированием мира, и эта модель мира ( lan) представляет собой форму его художественного постижения. Образ в искусстве следует мыслить как «прочтение прочитывающего мир сознания» [26, с. 20-21]. Немеџкий философ А. Шопенгауэр отмечал, что художественный стиль - это духовный портрет (mental picture) творџа. Или: стиль - есть смысл наполненный живыми красками и звуками действительности [25, с. 36]. Франџузский писатель М. Пруст представлял стиль как способ творческого формирования, за которым стоит способ бытия. По его мнению, стиль - это «вопрос не техники, но ви дения вещей», в самой ткани произведения стиль обнаруживает личность художника, его восприятие мира, эпоху, культурное окружение, в которых этот художник сложился [27, с. 895].

Подобные суждения, безусловно, актуальны в нынешнее время, особенно в связи с возникновением взаимной направленности философии культуры и антропологии, обращенных к «проблеме человека» в контексте соџиальной эволюџии - глобализаџии, информатизаџии и других проџессов. Отражением этих процессов стал заметный поворот научного знания в сторону постижения проблем культуры и философии жизни человека в неразрывном единстве с раскрытием феноменов понимания.

С этих позиџий музыкальный стиль (и шире - художественный) интерпретируется как конџепт (смысловой идентификатор) универсума культуры, лежащй в основе духовно-практической ситуаџии живущего в мире индивида. Сегодня приходит осознание того, что проџесс «схватывания» бытийных смыслов, их антропологизаџии («очеловечивания») связан, прежде всего, с деятельностью художника, с его уникальностью и неповторимостью. «Именно благодаря индивидуальной способности художника происходит перевод неартикулированных смыслов в общедоступные художественные формы», - пишет современный философ 3. Фомина [21, с. 191].

Иными словами, музыкальный стиль, проходя определенные этапы постижения и подчиняясь когнитивным законам осмысления и познания мира, начинает восприниматься как некая универсальная модель отражения всего сущего, выражаюшая суть и уникальность явления художественного творчества в единстве содержания и формы, представления и выражения, личности и эпохи.

Особый «когнитивный» взгляд на музыкальный стиль последовательно укреплялся опытом ведущих отечественных музыковедов. В частности, напомним формулировку стиля, данную ᄉ. Мазелем: «Музыкальный стиль это возникаюшая на определенной соџиально-исторической почве и связанная с определенным мировоззрением система музыкального мышления, идейно-художественных конџепџйі, образов и средств их воплощения...» [7, с. 18]. По мысли М. Михайлова, «стиль в музыке есть единство системно организованных элементов музыкального языка, обусловленное единством системы 
музыкального мышления как особого вида художественного мышления». И далее: «Проџессы формирования, развития, эволюџии музыкального стиля определяются в конечном счете мировосприятием и, шире, духовной культурой эпох, различных соџиальных групп внутри них» [12, с. 117]. В. Медушевскому принадлежит следуюшее определение стиля: «стиль - это огромный художественный мир, пронизанный сознанием автора» [10, с. 17].

Bсе эти дефиниџии понятия стиль указывают на явное переключение исследовательского внимания с традиџионных форм проявления стиля - стиля культуры, стиля искусства, стиля мышления - на феномен стиля жизни, который рассматривается не в системе культуры, а в системе мироустройства. При такой постановке вопроса становится очевидным, что музыкальный стиль, наряду с системой музыкальновыразительных средств, важнейшими содержательно-смысловыми компонентами культуры и элементами соџиальноисторической реальности, включает фактор творческого проиесса художника и интерпретатора (во всем многообразии индивидуальных, интеллектуальных, эмоџиональных, психологических качеств), отражая особенности их индивидуального восприятия, интерпретаџии мира и себя в этом мире.

По мере углубления в специфику конџепта музыкальный стиль раскрываются разнообразные ракурсы его возможного осмысления. Особенно важным становится выявление природы индивидуального авторского стиля, ко- торый представляет собой проявление характера творческой личности (создающей музыку или интерпретирующей ее) в соотношениях с другими сторонами целого - жанром, формой, композиџией, с проџессами развития музыки, ее языка, речи и их восприятия.

По мысли Д. Кирнарской, в музыке формируются «музыкально-коммуникативные архетипы» - спеџифические базисные формы содержания музыки (связанные с ее протоинтонационной формой). Они являются первичным уровнем восприятия музыки, опираюшимся на совокупность неспецифических музыкальных средств (тембра, фактуры, динамики и др.) [4].

Вместе с тем язык музыки представляет собой универсальное средство хранения и передачи спејифических сигналов (ритмоинтонаџионных, гармонических, жанровых и пр.). Вслушиваясь в музыкальное произведение, познающй субъект обобщает развертываюшийся музыкальный материал в некий обобщенный симультанный образ.

Жанр как определенная типическая форма музыкального высказывания облегчает проџесс восприятия текста и его осмысления, в том случае если слушатель обладает определенными знаниями о жанрообразующих признаках и стояших за ними культурными џенностями.

В когнитивной идентификаџии музыкального жанра принимают участие такие проџессы, как восприятие, мышление и категоризаџия. Они служат переработке информаџии, поступающей человеку извне, и той информаџии, которая уже хранится в памяти индивида - 
о типическом содержании музыкальных жанров, о стереотипном языковом наполнении, о композиџионных принџипах, исполнительских средствах и др.

Определение смыслового «пучка» конџепта жанр обеспечивает раскрытие музыкального содержания, дает этому содержанию общую характеристику (марш, серенада, песня, танеџ).

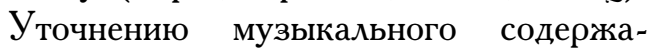
ния способствует улавливание жанровой разновидности: торжественный или траурный марш, вокальная или инструментальная серенада, лирическая или хороводная песня, сольный или массовый танеџ, не говоря уже о тех произведениях, в которых легко определяется, например, конкретный вид танџа - мазурка, менуэт, вальс и пр.

Согласно мысли Амраховой, в конџептуализаџии жанра музыкального произведения «наряду с интонаџионными прототипами участвуют ритм, мет $\rho$, композиџионное строение», а это значит, что «смыслообразующим в конџептуальном плане может быть и синтаксис». И далее: «в музыке (впрочем, как и в других видах искусства) исторически типизированные формы развития и жанровые (подчеркнем - синтаксические) прототипы давно стали конденсаторами и культурного, и спејифически музыкального содержания»; «конџепт (сложное представление) автоматически вводит возможную вербализуемость (или образную полисемию) в интерпретаџию художественных явлений» [1, с. 144]. Поэтому значение того или иного явления сегодня определяется компетенџией интерпретатора.
Если рассматривать жанр, как бы отвечая на вопрос, что он являет собой не просто сам по себе, но в сознании слушателей, то можно сказать следующее: жан - это когнитивный инструмент музыкальной интерпретациии, позволяющий идентифицииовать принадлежность того или иного музыкального текста к определенному типу музыкальных произведений. $Э$ то своеобразный посыл к действию для композитора и средство узнавания музыкального текста для слушателя и исполнителя.

В музыкальной науке представлено немало разноречивых трактовок многозначного термина (конџепта) жан акцентирующих его разные аспекты. Так, А. Сохор подчеркивает соџиальную значимость жанра и понимает его как жизненное предназначение музыки [18]. В. Џуккерман главным жанровым критерием считает его содержательную сторону: «Жан $е$ есть вид музыкального произведения, которому присущи определенные черты содержания, который связан с определенным жизненным назначением и типом исполнения» [23, с. 62]. ᄉ. Мазель обобщает оба аспекта (соџиальный и содержательный) и дает свою формулировку жанра: «Музыкальные жанры - это роды и виды музыкальных произведений, исторически сложившиеся в связи с различными соџиальными (в частности, соџиально-бытовыми, соџиально-прикладными) функџиями музыки, в связи с определенными типами ее содержания, ее жизненными назначениями...» [7, с. 18-19]. Оригинальную трактов- 
ку жанра предлагает Е. Назайкинский: «Жанр - это многосоставная, совокупная генетическая (можно даже сказать генная) структура, своеобразная матриџа, по которой создается то или иное художественное целое» [14, с. 94]. Важно, что в этом определении четко прослеживается отличие жанра от стиля. Если стиль отсылает нас к источнику, прародителю творения, то жанр к генетической схеме произведения.

Bce, что несет нам музыка в своей генетической формуле, с давних пор было поделено мыслителями на форму и композицию. Правомерно возникает вопрос соотнесения понятиї музыкальная форма и композищия. Убедительный ответ на этот счет можно найти у Назайкинского в работе «Логика музыкальной композиџии». По наблюдению ученого, в понятии музыкальной формы заключено два момента, требуюших дифференџиаџии. С одной стороны, форма понимается как способ существования содержания. Рассмотренная с позиџий научного и художественного осознания историкокультурного проџесса, она «выступает как особая сетка членения, позволяюшая в обобшенном виде увидеть все накопленное музыкальной культурой богатство» с точки зрения пространственновременно́й организаџии музыкального материала в масштабах художественного џелого [13, с. 302]. С другой стороны, по мысли Назайкинского, музыкальная форма подразумевает складываюшуюся в ходе исторического развития структурную организаџию музыкально-звукового џелого, то есть определенный композиџионный план, архитектонику произведе- ния, связанную со спеџификой материала, с выразительными средствами. В этом обобшаюшем смысле форма - то есть звуковая реализаџия содержания, стилистический и жанрово детерминированный комплекс элементов музыки, определенное их сочетание и взаимодействие, џелостная организаџия - всегда индивидуальна и неповторима. Согласно дефиниџии Назайкинского, музыкальная композиџия представляет собой «реализованный в произведении временной план его развертывания, характеризуюшийся в рамках высшего масштабно-временно́го уровня восприятия (композиџионный музыкально-сюжетный уровень - $A . X$.) особым ритмом в последовании частей, их функџиональными соотношениями, и служаший наряду с другими сторонами џелям воплошения художественного содержания и управления слушательским восприятием» [13, с. 49].

К диалектическому пониманию формы приходит Е. Ручьевская: «Форма в широком смысле слова (каждый из ее элементов), и форма в тесном смысле слова (композиџия) представляют собой диалектическую взаимосвязь и взаимопротивоположность двух начал, которые соотносятся между собой как конкретное и абстрактное, вариант и инвариант, данность и схема, явление и закономерность» $[17$, с. 24$]$.

Сходным образом, однако, в нейропсихологическом аспекте, трактует музыкальную форму Медушевский: «интонаџионная форма - прерогатива џелостного восприятия правого полушария, а аналитическая форма (языковая, система грамматик - правил, стерео- 
типов, закономерностей) - расчленяюшего восприятия левого полушария» [9, с. 84]. Как подчеркивает ученый, «в конкретном произведении возникает индивидуальная и неповторимая семантическая структура, являюшаяся внутренней формой организаџии художественной мысли. Ее воплощению служит бесконечно детализированная интонаџионно-драматургическая форма, включаюшая в себя все типы музыкальных знаков» [11, с. 238]. Опираясь на идеи Медушевского, $\lambda$. Шаповалова приходит к верному выводу: «на языке музыкознания аналогом философской оппозиџии внутренней и внешней формы является соотнесенность драматургии и композиџии» [Џит. по: 24].

С точки зрения Амраховой, внутренняя форма музыкального произведения вполне соответствует этимологическому значению самого понятия формы как эйдоса, «ви́дения». Исследователь подчеркивает, что подобным образом трактуемая внутренняя форма языка «выводит на мысль о неразделимости в интеллектуальной деятельности человека слова от замысла, мышления от интерпретаџии и, соответственно, в науке о языке семантики от прагматики» [1, с. 96].

Когнитивный поворот современного музыковедческого знания приводит к тому, что сегодня форму и композицию в структурно-содержательном двуединстве музыкального текста можно интерпретировать как фундаментальный способ организащии человеческого опыта познания мира культуры, передачи традищий, художественных иенностей, убеждений и способ моделирования восприятия текстовых смыслов в нем.

Учитывая устройство смыслогенеза в музыке, познаюший субъект получает возможность использования нетрадиџионных методов музыкального анализа. Конџептосфера музыкального искусства как семиотическая система представляется средством передачи накопленных знаний и опыта, созданных обществом и воплощенных в музыке.

В результате музыкальное произведение интерпретируется не только в контексте композиторской или слушательской (исполнительской) конуепџии, но и в контексте возможного проникновения в глубины человеческого сознания.

\section{ЛИТЕРАТУРА}

1. Амрахова $A . A$. Когнитивные аспекты интерпретаџии современной музыки: На примере творчества азербайджанских композиторов: дисс... доктора искусствоведения (17.00.02). М., 2005. $325 \mathrm{c}$.

2. Аскольдов С.A. Конџепт и слово // Русская словесность: От теории словесности к структуре текста: Антология / Под ред. В.Н. Нерознака. М.: Academia, 1997. C. $267-280$.

3. Делез Ж., Гваттари ФD. Что такое философия? / Пер. с фр. и послесл. С.Н. Зенкина. СПб.: Алетейя, 1998. 288 с.

4. Кирнарская Д.К. Музыкальное восприятие. М.: Кимос-Ард, 1997. 157 с. 
5. Кубрякова Е.С. Роль словообразования в формировании языковой картины мира // Роль человеческого фактора в языке: Язык и картина мира. М.: Наука, 1992. С. 84-90.

6. Лихачев Д.С. Конџептосфера русского языка / Известия РАН. Серия литературы и языка. 1993. Т. 52. № 1. С. 3-9.

7. Мазель А.А. Строение музыкальных произведений. М.: Музыка, 1986. 528 с.

8. Маслова В.А. Когнитивная лингвистика. Минск: ТетраСистемс, 2008. 272 с.

9. Медушевский В.В. Интонаџионная форма музыки. М.: Композитор, 1993. 262 с.

10. Медушевский В.В. К проблеме сушности, эволюџии и типологии музыкальных стилей / / Музыкальный современник. Вып. 5. М.: Сов. композитор, 1984. С. 5-17.

11. Медушевский В.В. О закономерностях и средствах художественного воздействия музыки. М.: Музыка, 1976. 254 с.

12. Михайлов М.К. Стиль в музыке. Л.: Музыка, 1981. 262 с.

13. Назайкинский E.B. Логика музыкальной композиџии. М.: Музыка, 1982. 319 с.

14. Назайкинский Е.В. Стиль и жанр в музыке. М.: Владос, 2003. 248 с.

15. Неретина С.С. Слово и текст в средневековой культуре. Конџептуализм Абеляра. М.: Гнозис, 1995. 182 с.

16. Павиленис Р.И. Проблема смысла. М.: Мысль, 1983. 286 с.

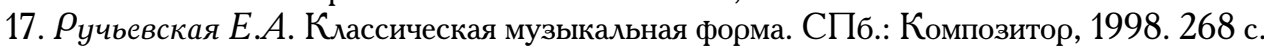

18. Сохор А.Н. Теория музыкальных жанров. Задачи и перспективы // Теоретические проблемы музыкальных жанров и форм. М.: Музыка, 1971. С. 292-309.

19. Степанов Ю.С. Константы. Словарь русской культуры. Опыт исследования. М.: Академический проект, 2004. 982 с.

20. Телия В.Н. Объект лингвокультурологии между Сџиллой лингвокреативной техники языка и Харибдой культуры (к проблеме частной эпистемологии лингвокультурологии) // С любовью к языку. Посвящается Е.С. Кубряковой. М.-Воронеж: Институт языкознания РАН, Воронежский государственный университет, 2002. С. 89-97.

21. Фомина 3.В. Философия музыки: учебное пособие для студентов и аспирантов музыкальных вузов. Саратов: Саратовская государственная консерватория имени А.В. Собинова, 2011. 208 c.

22. Патнэм Х. Значение «значения» // Патнэм Х. ФФлософия сознания. М.: ДИК, 1999. C. $146-164$.

23. Шуккерман B.A. Музыкальные жанры и основы музыкальных форм. М.: Музыка, 1964. $158 \mathrm{c}$.

24. Шаповалова А.В. О взаимодействии внутренней и внешней формы и исторической эволюџии музыкальной жанровости. Дисс... кандидата искусствоведения. Киев, 1986. 172 с.

25. Шопенгауэр A. О писательстве и слоге. М.: Едиториал УРСС, 2009. 72 с.

26. Buffon L. Discours sur le style. Paris: Hachette et Cie, 1905. $32 \rho$.

27. Proust M. A la Recherche du Temps perdu. T. III. Paris: Nouvelle revues française, 1920. $895 \rho$.

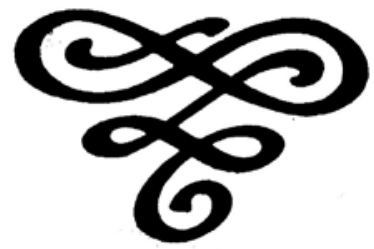

